\title{
EFEKTIVITAS PENGGUNAAN MODUL TERHADAP HASIL BELAJAR PADA MATA PELAJARAN DASAR PERANCANGAN TEKNIK MESIN KELAS X SMK SEMEN PADANG
}

\section{THE EFFETIVENESS OF USING MODULES ON LEARNING OUTCOMES IN THE BASIC SUBJECTS OF MECHANICAL ENGINEERING DESIGN GRADE X SMK SEMEN PADANG}

\author{
Putri Nurhalimah Erdi ${ }^{(1)}$, Nelvi Erizon ${ }^{(2)}$, Arwizet $K^{(3)}$, Primawati ${ }^{(4)}$. \\ Jurusan Teknik Mesin, Fakultas Teknik, Universitas Negeri Padang \\ Kampus Air Tawar, Padang 25131, Indonesia \\ putri.nurhalimah07@gmail.com \\ nelvi_erizon@yahoo.com \\ arwizet@yahoo.com \\ primafazma@gmail.com
}

\begin{abstract}
Abstrak
Pembelajaran yang tidak kreatif dan monoton akan membuat siswa menjadi malas belajar dan kurang berimajinasi dalam mengembangkan idenya serta mengakibatkan hasil belajar siswa menjadi rendah. Guru juga dituntut untuk menjadi lebih kreatif agar siswa mudah memahamimaterinya. Tujuan penelitian ini adalah untuk mengetahui dan mendeskripsikanapakah efektif pembelajaran menggunakan modul dengan pembelajaran menggunakan model langsung terhadap hasil belajar siswa pada kelas eksperimen dan kelas kontrol pada mata pelajaran Da sar Perancangan Teknik Mesin Kelas X SMK Semen Padang. Populasi dalam penelitian ini adalah seluruh kelas $X$, yaitu kelas X TM 1, X TM 2 dan X TM 3 yang masing-

masing kelas berjumlah 28 siswa tahun ajaran 2018/2019. Sedangkan sampel dalam penelitian ini adalah siswa kelas X TM 1 sebagai kelas kontrol dan X TM 2 sebagai kelas ekperimen yang masing-masing kelas berjumlah 28 siswa. Penelitian ini menggunakan pendekatan kuantitatif dan metode yang digunakan dalam penelitian ini adalah quacy eksperimen (eksperimen semu), serta pengambilan data dilakukan melalui tes tertulis yaitu pretest dan postest. Analisis data uji normalitas, uji homogenitas variansi, uji reliabilitas, serta uji perbandingan model menggunakan uji hipotesis, data yang terkumpul tersebut di olah dan dianalisis secara statistik dengan bantuan komputer program MINITAB versi 16 for windows dan Microsotf Excel.

Dari analisis data terhadap hasil belajar dapat disimpulkan bahwa pembelajaran menggunakan modul bagi siswa lebih baik dana efektif dari pada pembelajaran dengan menggunakan metod e langsung. Serta perbedaan skor hasil belajar terhadap penggunaan modul dana menggunaka $\mathrm{n}$ metode langsung terlihat secara signifikan.
\end{abstract}

Kata Kunci: Efektivitas, Hasil Belajar, Modul, Langsung, Dasar Perancangan Teknik Mesin.

\begin{abstract}
Monotonous and non-creative learning makes students lazy to learn and lack imagination and results in low student learning outcomes. Teachers are also required to be more creative so students easily understand the material. The purpose of this study is to find out and describe whether effective learning uses modules with learning using a direct model of student learning outcomes in the experimental class (module) and control class (direct) in the basict subject mechanical engineering of design grade X SMK Semen Padang. The population in this study was all class X, namely classes X TM 1, X TM 2, and X TM 3 with each class totaling 28 students in the academic year 2018/2109. While the sample in this study were class X TM 1 students as a control
\end{abstract}


class and X TM 2 as an experimental class with each class numbering 28 students. This study uses a quantitative approach and the method used in this study is quacy experiment (quasi experiment), and data collection were carried out through written tests, namely pretest and posttest. Analysis of normality test data, variance homogeneity test, reliability test, and model comparison test using hypothesis testing, the collected data was processed and analyzed statistically with the help of the MINITAB computer program version 16 for windows and Microsoft Excel. From data analysis on learning outcomes it can be concluded that learning using modules for students is better and more effective than learning using direct methods. As well as differences in the score of learning outcomes with the use of modules and using the direct method are seen significantly.

Keywords: Effectiveness, Learning Outcomes, Module, Direct, Basict Subject Mechanical Engineering Of

Design.

\section{Pendahuluan}

Belajar adalah sebuah proses perubahan tingkah laku sebagai hasil dari interaksinya terhadap lingkungan dalam memnehi kebutuhannya (Sugihartono:2007).

Pembelajaran merupakan uapaya yang dilakukan oleh pendidikan dengan unsur sengaja yang dapat mengakibatkan proses dalam sebuah kegiatan belajara (Sudjana dalam Sugihartono:2007).

Pendidikan adalah wahana untuk meningkatkan dan mengembangkan kualitas serta sumber daya manusia. Pendidikan diharapkan mampu memberikan perubahan pada diri individu, yaitu prubahan aspek kognitif, afektif, dan psikomotor (Jasman dkk: 2018).

Sekolah adalah sebuah lembaga pendidikan yang proses belajar mengajar berlangsung.

Melalui prosesa inillah tujuana pendidikan akan tercapai dalam bentuk perubahan perilaku siswa (Ambiyar dkk: 2016).

Efektivitas adalah memberikan penilaian tindkan prilaku atau sebah agennda yang telah diakukan dengan menghasilkan sesuatu seperti yang sudah direncanakan dan belajar sesuai dengan sebenarnya serta tidak adanya penyimpangan dari perencnaan tersebut sehingga sesuia dengan tujuan yang telah ditetapkan (Nelvi Erizon dkk: 2019).

Modul meruppakan sesuatu unit yang lengkap yang berdiri senidri dan terdiri atas rangkaian kegiatan belajar yang disusun untuk membantu siswa untuk mencapai

tujuan yang ditetapkan secara khusus dan jelas (Nasution dalalm buku Suparno:2017). Proses belajar mengajar pada hakikatnya adalah praktek komunikasi dimana praktek antara sumber pesan ke penerima pesan. Kualitas suatu pendidikan dalam sebuah sekolah ditentukan oleh kualitas dalam sebuah proses pembelajaran. Dari setiap banyak unsur sarana pendidikan yang ada disekolah yang sangat menentukan adalah kualitas buku pelajaran yang ada disekolah. Karna kenyataannya buku pelajaran adalah jantung pembelajaran.

Faktor lain yang juga akan menjadi kualitas dalam sebuah pembelajaran adalah kreatifnya seorang guru. Guru yang kreatif akan mengembangkan sendiri materi pelajarannya, namun pada kenyataannya adalah mayoritas guru disekolah masih mengjara sesuai dengan apa yang ada didalam buku pelajaran atau bias disebut Teks Book.

Keaktifan siswa menjadi sedikit terhambat karena siswa hanya belajar mencatat mata pelajaran yang diajarkan oleh guru, serta mereka kurang dilatih untuk berfikir kreatif dari pelajaran yang diajarkan oleh guru. Tingkat kebosanan siswa pada saat mengikuti proses belajar mengajar cenderung akan lebih tinggi diakibatkan kurangnya motivasi dan minat siswa dalam belajar.

Tingkat pemahaman siswa yang bervariasi dalam system belajar membutuhkan penjela san yang lebih sehingga mengakibatkan rendahnya kemandirian siswa dalam

belajar. Serta belum tersedianya bahan ajar yang memadai untuk menunjang kegiatan proses belajar mengajar dikelas yang bertujuan

sebagai pegangan bagi siswa dalam belajar sehingga dapat meningkatkan motivasi dan minat siswa dalam belajar.

Kelas X di Jurusan Teknik Permesinan SMK Semen Padang tahun ajaran 2018/2019 pada mata pelajaran Dasar Perancangan Teknik Mesin terlihat adanya permasalahan prestasi 
dan minat siswa dalam belajar. Banyaknya siswa yang belum mengerti terhadap materi yang disampaikan guru secara langsung dan meningkatkan rasa bosan akibat pembelajaran yang monoton.

Hasil rata-rata nilai Ujian Tengah Semester Genap kelas X pada mata pelajaran Dasar Perancangan Teknik Mesin tergolong masih rendah karna rata-rata seluruh kelas masih berada dibawah KKM yaitu 75. Pemilihan model pembalajran akan sangat mempengaruhi suatu proses belajar mengajar. Rata-rata nilai Ujian Tengah Semester Genap mata pelajaran Dasar Perancangan Teknik Mesin kelas X Jurusan Teknik Permesinan SMK Semen Padang adalah sebagai berikut:

Tabel 1. Rata-rata hasil Ujian Tengah Semester Genap masing-masing kelas X SMK Semen Padang.

\begin{tabular}{|c|c|c|}
\hline X TM 1 & X TM 2 & X TM 3 \\
\hline 45,54 & 51,32 & 45 \\
\hline
\end{tabular}

Kelas X SMK Semen Padang memiliki total siswa sebanya 84 siswa, dari tabel diatas dapat dikatakan bahwa hasil belajar siswa tersebut belum berhasil karena rata-rata hasil belajar siswa setiap kelas masih tergolong dibawah atau kurang dari 75. Hasil belajar siswa akan tergolong berhasil apabila ratarata hasil belajar siswa setiap kelas sama atau diatas 75. Sehingga dapat disimpulkan bahwa masih banyak nilai siswa yang yang belum mencapai indeks kriteria ketuntasan minimial (KKM) yang telah ditentukan yaitu 75 pada mata pelajaran Dasar Perancangan Teknik Mesin.

Model pembelajaran yang mengonsepkan untuk keaktifan siswa dalam bentuk sebuah kerjasama kelompok untuk mencapai sebuah tujuan pembelajaran disebut pembelajaran kolaboratif. Pembelajaran kolaboratif memiliki banyak manfaat apabila diterapkan dalam sebuah pembelajaran, karna pembelajaran ini akan membuat sswa menjadi lebih berpikir kreatif, mandiri serta akan melakukan komunkasi yang banyak dengan guru . pembelajaran kolaboratif akan membuat siswa untuk menyampaikan idenyya didepan siswa yang lain serta menambah wawasan untuk masing-masing siswa.

Pembelajaran kolaboratif yang penulis maksud adalah pembelajaran yang menggunakan modul, dimana setiap siswa akan diberikan modul dan siswa akan dibentuk menjadi beberapa kelompok untuk memecahkan masalah yang diberikan dengan menjadikan modul sebagai bahan pedoman siswa. Apabila siswa tersebut berhasil memecahkan masalah yang telah diberikan, maka siswa dipersilahkan untuk maju kedepan agar mempresentasikan hasil nya didepan siswa yang lain agar siswa yang lain juga bisa memberikan tanggapan dan masukan terhadap jawaban yang diberikan temannya.

Hasil belajar akan menggambarkan perubahan yang dialami oleh siswa, baik itu tingkah laku dari buruk menjadi baik ataupun perubahan pengetahua dari tidak tahu menjadi tahu (Oemar Hamalik:2007).

Metode langsung adalah metode yang cara penyampiannya disampaikan secara langsung dengan lisan oleh guru kepada siswa. Sehingga pembelajaran seperti ini akan membuat siswa menjadi cenderung lebih bosan dan membuat siswa menjadi kurang paham dengan pelajaran yang dijalaninya karena kurangnya dorongan dari guru. Siswa hanya dituntut untuk mencatat dan mnghafal materi yang telah disampikan oleh guru. Pemebalajran langsung akan membuat siswa menjadi kurang mandiri karna hanya menerima dari yang diberikan guru tanpa dikembangkan dan berusaha sendiri.

Masalah-masalah yang diuraikan pada latar belakang dapat diidentifikasikan sabagi berikut:'

1. Kurangnya minat siswa dalam mengikuti pembelajaran.

2. Kemandirian siswa dalam mengikuti pembelajaran masih kurang.

3. Tingkat pemahaman siswa yang bervariasi membutuhkan penjelasan yang lebih, sehingga guru membutuhkan tenaga tambahan untuk mengajar agar siswa menjadi lebih udah untuk memahami

4. Kurangnya penggunaan media pembelaj aran yang mendukung kemudahan siswa untuk belajar. 
Tujuan penelitian ini adalah:

1. Mendeskripsikan hasil belajar menggunakan Modul pada mata pelajaran

Dasar Perancangan Teknik Mesin kelas

$X$ SMK Semen Padang.

2. Mendeskripsikan hasil belajar dengan menggunakan metode langsung pada mata pelajaran Dasar Perancangan teknikMesin kelas $\mathrm{X}$ SMK Semen Padang.

3. Mendeskripsikan apakah efektif penggunaan moduldari pada pada metode langsung yang dilihat dari pengingkatan hasil belajar pada kelas Eksperimen dan kelas Kontrol kelas X SMK Semen Padang.

\section{Metode Penelitian}

Berdasarkan permasalahan, pembatasan masalah dan tujuan penelitian yang diiungkapkan sebelumnya yang akan diteliti dan tujuan yang ingin dicapai, maka penelitian ini menggunakan pendekatan kuantitatif dan metode yang digunakan dalam penellitian ini adalah quasy eksperiment (eksperimen semu). Sebagaimana yang diungkapkan oleh Mohamad Nazir (2005:86), bahwa quasy eksperiment adalah penelitian yang mendekati percobaan sungguhan dimana tanpa adanya kontrol ketat atau memanipulasi semua variable yang relevan, dan menentukan validitas internal dan eksternal sesuai dengan bahasan-bahasan yang ada.

Penelitian dilakukan di SMK Semen Padang Kelas X pada semester Januari - Juni Tahun Ajaran 2018/2019. Dengan waktu penelitian yaitu 18 Maret s/d 30 April 2019 yang masing-masing kelas berjumlah 28 siswa.

\section{A. Prosedur Penelitian}

Penelitian ini merupakan penelitian yang bertujuan untuk mengetahui efektivitas penggunaan modul terhadap hasil belajar, prosedur perencanaan penelitian sebagimana yang terlihat ditabel dibawah ini:

Tabel 2. Rencana Penelitian

\begin{tabular}{llll}
\hline Kelas & Pretest & Perlakuan & Postest \\
\hline X TM 1 & $\mathrm{Y}_{1}$ & $\mathrm{O}_{1}$ & $\mathrm{X}_{1}$ \\
\hline X TM 2 & $\mathrm{Y}_{2}$ & $\mathrm{O}_{2}$ & $\mathrm{X}_{2}$
\end{tabular}

Keterangan:

$\mathrm{O}_{1}$ : Perlakuan model pembelajaran langsung

$\mathrm{O}_{2}$ : Perlakuan dengan menggunakan Modul

$\mathrm{X}_{1}$ : Perlakuan tes awak terhadap keseluruhan kelas sampel

$\mathrm{X}_{2}$ : Perlakuan tes akhir terhadao keseluruhan kelas sampel

Rancangan penelitian ini dilakukan dengan langkah-langkah sebagai berikut:

1. Melakukan tes awal (pretest) terhadap kelompok siswa yang sama mendapatkan perlakuan.

2. Memberikan perlakuan dengan menggunakan modul pada kelas Eksperimen.

3. Memberikan perlakuan Langsung pada kelas Kontrol.

4. Kegiatan belajar dilaksanakan tiga kalli pertemuan, yitu satu kali pertemuan satu kali tatap muka.

5. Melakukan tes akhir (postets) terhadap kelompok kelas setelah selesai diberikan perlakuan yang berbeda.

\section{B. Instrumentasi}

Instrumen adalah alat pada waktu penelitian yang akan diberikan kepada kelas sampel untuk memperoleh data tentang hasil belajar siswa. Instrumen yang dilakukan adalah menggunakan silabus, RPP, modul dan soal latihan.

Pelaksaan tindakan uji coba dilakukan dikelas XI SMK Semen Padang yang ketika duduk di Kelas $\mathrm{X}$ siswa tersebut juga mempelajari mata pelajaran dan materi tersebut yang jumlah siswa juga sebanyak 28 siswa. Adapun analisis uji coba instrumen adalah sebagai berikut:

\section{Menghitung Indeks Pembeda Soal}

Indeks Pembeda $\left(\mathrm{I}_{\mathrm{p}}\right)$ dihitung untuk melihat apakah soal-soal yang dibuat dapat membedakan kemampuan peserta didik atau tidak. Cara untuk menghitung indeks pembeda yaitu: mengurutkan data dari nilai tertinggi sampai nilai terendah, mengambil $27 \%$ daari jumlah siswa yang tergoolong tinggi dan $27 \%$ dari jumlah siswa yang tergolong rendah dengan rumus:

$$
n_{t}=n_{r}=n=27 \% \times N
$$


Setelah mendapatkan $27 \%$ dari siswa, selanjutnya menghitung degress of freedom (v) dengan rumus:

$$
d_{f}=\left(n_{t}-1\right)+\left(n_{r}-1\right)
$$

Selanjutnya menentukan indeks pembeda soal menggunakan rumus yang dinyatakan oleh Prawironegoro (1985:11) denganrumus:

$$
I_{p}=\frac{M_{t}-M_{r}}{\sqrt{\frac{\sum x_{t}^{2}+\sum x_{r}^{2}}{n(n-1)}}}
$$

$I_{p} \quad=$ Indeks Pembeda Soal

$M_{t} \quad=$ Rata-rata skor kelompok

tinggi

$M_{r} \quad=$ Rata-rata skor kelompok

rendah

$\sum x_{t}^{2} \quad$ Jumlah kuadrat deviasi skor

kelompok tinggi

$\sum x_{r}^{2}=$ Jumlah kuadrat deviasi skor kelompok rendah

Keterangan:

\section{Menghitung Indeks Kesukaran}

Indeks kesukaran soal digunakan untuk me lihat apakah soal termasuk kategor sukar, sedang, atau mudah dengan menggunakan rumus:

$$
I_{k}=\frac{D_{t}+D_{r}}{2 m n} \times 100 \%
$$

Keterangan:

$I_{k} \quad=$ Indeks kesukaran

$D_{t} \quad=$ Jumlah skor kelompok tinggi

$D_{r} \quad=$ Jumlah skor kelompok rendah

$M \quad=$ Skor setiap soal jika benar

$N \quad=27 \% \times \mathrm{N}$

$\mathrm{N} \quad=$ Banyaknya pengikut tes

3. Menghitung Reliabilitas Tes

Reliabilitas tes adalah ukuran yang menentukan tes tersebut dapat dipercaya dan mendapatkan hasil yang konsisten dengan rumus:

$$
r_{11}=\left(\frac{n}{n-1}\right)\left(1-\frac{\sum \sigma_{i}^{2}}{\sigma_{t}^{2}}\right)
$$

Dengan:

$$
\sigma_{i}^{2}=\frac{\sum x_{i}^{2}-\frac{\left(\sum x_{i}\right)^{2}}{N}}{N}
$$

Keterangan:

$r_{11}=$ Reliabilitas yang dicari

$\sum \sigma_{i}{ }^{2}=$ Jumlah variansi skor tiap-tiap item

$\sigma_{t}{ }^{2} \quad=$ Variansi total

$n \quad=$ Banyak soal

$\mathrm{N} \quad=$ Banyak pengikut tes

$\sum x=$ Jumlah skor tiap butir soal

$\sum x_{i}{ }^{2}=$ Jumlah kuadrat skor tiap butir soal

\section{Teknik Analisis Data}

Data yang telah dikumpulakn dalam penelitian ini akan diolah dan dianalisis secara kuantitatif. Uji prasyarat analisis dilakukan dengan cara mengolah data yang telah didapatkan dengan cara melakukan uji normalitas, uji homogenitas variansi, serta uji hipotesis dengan menggunakan bantuan software MINITAB.

1. Uji Normalitas

Uji normalitas bertujuan untuk melihat apakah data berdistribusi normal atau tidak. Uji yang dilakukan adalah uji AndersonDarling. Data dinyatakan berdistribusi normal jika nilai $\mathrm{P}$ yang diperoleh lebih besar dari taraf nyata $(\alpha=0,05)$. Jika sebaliknya maka data tidak berdistribusi normal.

\section{Uji Homogenitas Variansi}

Uji homogenitas variansi bertujuan untuk mengetahui apakah kedua dataa memiliki variansi yang homogen atau tidak. Uji ini dilakukan dengan menggunakan Uji F. Data dikatakan homogen jika nilai $\mathrm{P}$ lebih besar dari pada taraf nyata yang ditetapkan yaitu 0,05 . Jika sebaliknya maka data tidak memiliki variansi homogen. 


\section{Uji Hipotesis}

Uji hipotesis bertujuan untuk mengetahui apakah hipotesis penelitian diterima atau ditolak, atau apakah kemampuan penalaran matematis peserta didik pada kelas eksperimen lebih baik dari pada kemampuan penalaran matematis peserta didik pada kelas kontrol. Pada penelitian ini data dari hasil belajar diketahui berdistribusi normal dan homogeny. Maka uji kesamaan dua rata-rata menggunakan uji-t dengan rumus:

$$
t=\frac{\bar{x}_{1}-\bar{x}_{2}}{s \sqrt{\frac{1}{n_{1}}+\frac{1}{n_{2}}}}
$$

Dengan

$$
s^{2}=\frac{\left(n_{1}-1\right) s_{1}{ }^{2}+\left(n_{2}-1\right) s_{2}^{2}}{n_{1}+n_{2}-2}
$$

Keterangan:

$$
\begin{array}{ll}
\overline{x_{1}} & \text { : Rata-rata nilai kelas ekperimen } \\
\overline{\mathrm{x}_{2}} & \text { : Rata-rata nilai kelas kontrol } \\
\mathrm{n}_{1} & \text { : Jumlah siswa kelas eksperimen } \\
\mathrm{n}_{2} & \text { : Jumlah siswa kelas kontrol } \\
\mathrm{s}_{1} & \text { : Simpangan baku kelas ekperimen } \\
\mathrm{s}_{2} & \text { : Simpangan baku kelas kontrol } \\
\mathrm{S} & \text { : Simpangan baku gabungan }
\end{array}
$$

\section{Hasil Penelitian}

\section{A. Deskripsi Data}

Penelitian ini dilaksanakan di SMK Semen Padang mulai tanggal 18 Maret sampai 30 April 2019. Populasi dalam penelitian ini adalah siswa kelas X TM 1 dan X TM 2 yang masing-masing kelas berjumlah 28 siswa.

\section{Deskripsi Data Hasil Belajar Soal Uji Coba}

Soal yang diujikan terlebih dahulu dilakukan uji coba ke kelas yang terlebih dahulu sudah mempelajari materinya, yaitu dalam penelitian ini soal pretest dan posttest diujicobakan dikelas XI SMK Semen Padang. Tujuannya untuk melihat indeks pembeda, indeks kesukaran dan reliabilitas tes.

Tabel 3. Klasifikasi Soal Uji Coba

\begin{tabular}{llllll}
\hline No & Ip & Ik & Ket & Var & Reli \\
\hline 1 & 2.33 & $26 \%$ & Sukar & 0.58 & \\
\cline { 1 - 5 } 2 & 2.24 & $85 \%$ & Mudah & 0.41 & \\
\cline { 1 - 5 } 0 & 2.26 & $90 \%$ & Mudah & 0.19 & \\
\cline { 1 - 4 } 4 & 2.25 & $43 \%$ & Sedang & 0.69 & \\
\cline { 1 - 5 } 5 & 2.26 & $82 \%$ & Mudah & 0.20 &
\end{tabular}

Berdasarkan tabel diatas dapat disimpulkan bahwa soal pertanyaan sebanyak lima buah tersebut memiliki indeks pembeda dan indeks kesukaran yang bervariasi, serta memiliki reliabiltas sedang dengan nilai sebesar 0.4399 .

\section{Deskripsi Data Hasil Belajar Menggunakan Modul}

Pembelajaran yang dilaksanakan pada kelas eksperimen yaitu kelas X TM 2 adalah menggunakan model pembelajaran menggunakan modul. Waktu yang digunakan dalam penelitian adalah 2 kali (4 $\mathrm{x}$ 45).

Pelaksaan pembelajaran pada kelas eksperimen awalnya dilakukan pretest dengan jumlah soal sebanyak 5 soal, ratarata hasil belajar 61,43 dengan jumlah siswa 28 orang. Soal tersebut dilakukan untuk mengetahui pengetahuan awal dari masingmasing siswa. Dan setelah dilakukan perlakuan maka diberikan tes yaitu posttest dengan jumlah rata-rata hasil belajar 84,64 dengan jumlah siswa 28 orang.

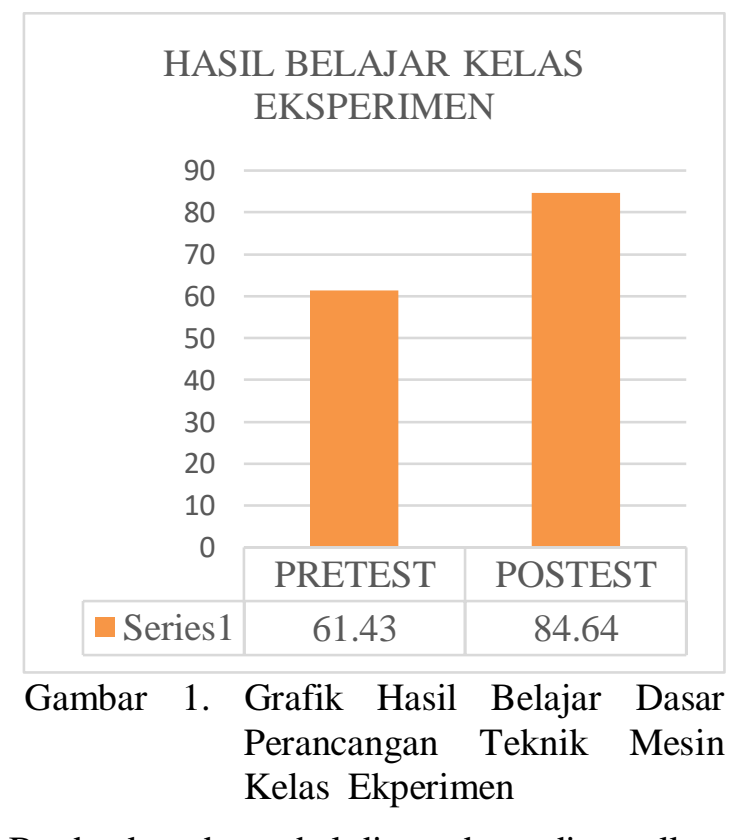

Berdsarkan data tabel diatas dapat dismpulkan bahwa pembelajaran menggunakan modul 
merupakan pembelajaran yang baik untuk menunjang hasil belajar siswa yang memiliki perbedaan naik skor rata-rata menjadi 23.21.

3. Deskripsi Data Hasil Belajar Model Pembelajaran Langsung

Pembelajaran yang dilaksanakan di kelas control yaitu kelas $\mathrm{X} \quad \mathrm{TM} \quad 1$ yaitu menggunakan model pembelajaran langsung, yaitu dengan metode ceramah dan tanya jawab. Dalam proses belajar ini waktu yang digunakan dalam guru mata pelajaran adala 2 kali pertemuan (4 x 45).

Pelaksanaan pembelajaran pada kelas control pada awalnya dilakukan pretest dengan jumlah soal 5 soal, rata-rata nilai hasil belajar

58,94 dengan jumlah siswa 28 orang. Soal terebut dilakukan untuk mengetahui pengetahuan awal dari masing-masing siswa. Dan setelah dilakukan perlakuan maka diberikan tes yaitu posttest dengan jumlah rata-rata hasil belajar 78,39 dengan jumlah siswa 28 orang.

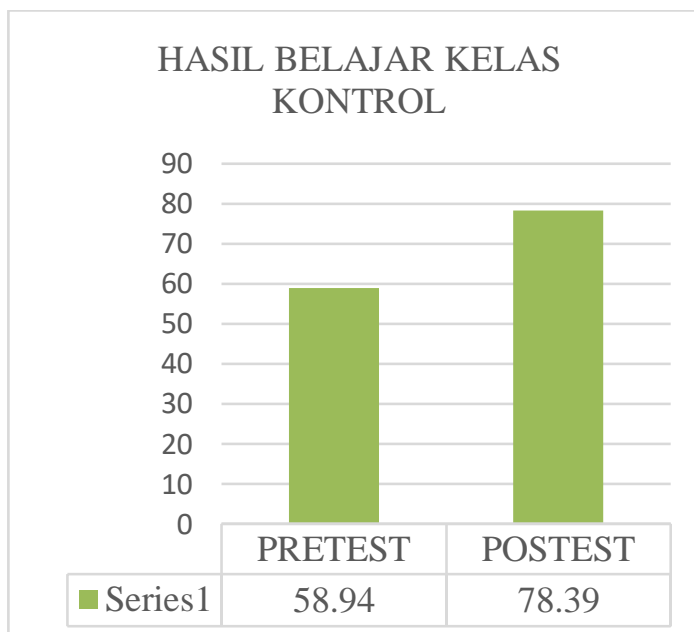

Gambar 2. Grafik Hasil Belajar Dasar Perancangan Teknik Mesin Kelas Kontrol

4. Deskripsi Data Perbedaan Hasil Belajar Kelas Eksperimen (Modul) dan Kelas Kontrol (Langsung).

Analisis data perlu adanya pengujian prasyarata analisis terlebih dahulu. Dalam penelitian ini prasyarat yang diterapkan adalah uji normalitas, uji homogenitas dan uji-t. Berikut hasil uji prasyarat analisis dalam penelitian ini:

\section{a. Pretest}

\section{1). Uji Normalitas}

Uji normalitas dilakukan dengan uji Anderson-Darling. Pada kelas eksperimen di peroleh p-value 0,082 dan pada kelas kontrol diperoleh P-value 0,318. Tes dikatakatan normal apabila p-Value > 0,05 dan dikatakan tidak normal apabila pValue $<0,05$. Karena P-value pada kelas eksperimen dan kelas control lebih dari taraf nyata, $\quad \alpha=0,05, \quad$ maka dapat disimpulkan data tes kedua kelas sampel berdistribusi normal.

Tabel 3. Hasil Uji Normalitas Pretest

\begin{tabular}{llll}
\hline No & Kelompok & p-Value & Kesimpulan \\
\hline 1 & Kelas & 0,082 & Normal \\
& Ekperimen & & \\
\hline 2 & Kelas Kontrol & 0,318 & Normal \\
\hline
\end{tabular}

\section{2). Uji Homogenitas Variansi}

Uji homogenitas variansi dilakukan dengan uji-F. dari hasil perhitungan diperoleh nilai $\mathrm{P}$-value sebesar 0,632 , hal ini berarti $\mathrm{P}$ value $>\alpha$ (taraf nyata $=0,05)$ maka dapat disimpulkan $H_{0}$ diterima atau dapat dikatakan variansi pada kedua kelas sampel homogen.

\section{3). Uji Hipotesis}

Uji-t pretest kelas ekperimen dan pretest kelas control. Analisis Two-Sample T-Test and $C I$ terhadap pretes kelas eksperimen dan kelas control bertujuan untuk mengetahui ada tidaknya perbedaan yang signifikan nilai pretest kelas eksperimen dan kelas kelas control. Kesimpulan penelitian dinyatakan signifikan apabila $\mathrm{t}$ hitung $>\mathrm{t}$ tabel pada taraf signifikan $5 \%$ dan nilai $\mathrm{p}<0,05$.

Ringkasan uji $\mathrm{t}$ pretest terlihat bahwa $\mathrm{t}$ hitung adalah 1,39 sedangkan $\mathrm{t}$ tabel 2,14 $(1,39<\quad 2,14)$ dengan probabilitas 0,085 untuk kelas eksperimen dan kelas control. Oleh karena probabilitas 0,085 $>0,05$, maka $\mathrm{H}_{0}$ di terima, maka dapat disimpulkan bahwa tidak terdapat perbedaan skor yang berarti.

b. Postest 
1). Uji Normalitas

Uji normalitas dilakukan dengan uji Anderson-Darling. Pada kelas eksperimen di peroleh p-value 0,264 dan pada kelas kontrol diperoleh P-value 0,225. Karena Pvalue pada kelas eksperimen dan kelas control lebih dari taraf nyata, $\alpha=0,05$, maka dapat disimpulkan data tes kedua kelas sampel berdistribusi normal.

Tabel 4. Hasil Uji Normalitas Postest

\begin{tabular}{llll}
\hline No & Kelompok & p-Value & Kesimpulan \\
\hline 1 & Kelas & 0,264 & Normal \\
& Ekperimen & & \\
\hline 2 & Kelas & 0,225 & Normal \\
& Kontrol & & \\
& & &
\end{tabular}

\section{2). Uji Homogenitas Variansi}

Uji homogenitas variansi dilakukan dengan uji-F. dari hasil perhitungan diperoleh nilai $\mathrm{P}$-value sebesar 0,701, hal ini berarti Pvalue $>\alpha$ (taraf nyata $=0,05)$ maka dapat disimpulkan $H_{0}$ diterima atau dapat dikatakan variansi pada kedua kelas sampel homogen.

\section{3). Uji Hipotesis}

Uji-t pretest kelas ekperimen dan pretest kelas control. AnalisisaTwo-Sample T-Test and $C I$ terhadap pretest kelas eksperimen dan kelas control bertujuan untuk mengetahui ada tidaknya perbedaan yang signifikan nilai pretest kelas eksperimen dan kelas kelas control. Kesimpulan penelitian dinyatakan signifikan apabila $\mathrm{t}$ hitung $>\mathrm{t}$ tabel pada taraf signifikan 5\% dan nilai $\mathrm{p}<0,05$.

Ringkasan uji $\mathrm{t}$ pretest terlihat bahwa $\mathrm{t}$ hitung adalah 2,08 sedangkan $\mathrm{t}$ tabel 2,14 $(2,08<2,14)$ dengan probabilitas 0,021 untuk kelas eksperimen dan kelas control. Oleh karena probabilitas0,021 $<0,05$, maka $\mathrm{H}_{\mathrm{a}}$ di terima, maka dapat disimpulkan bahwa terdapat perbedaan skor yang berarti secara signifikan pada kelas eksperimen dan kelas control.

\section{Kesimpulan}

Model pembelajaran menggunakan modul dapat membuat hasil belajar siswa lebih tinggi dibandingkan dengan model pembelajaran langsung pada mata pelajaran Dasar Perancangan Teknik Mesin kelas X SMK Semen Padang. Hal ini dapat terlihat daru perbedaan nilai pada kelas eksperimen yang memiliki nilai pretest rata-rata 58,31 dan nilai posttest memiliki rata-rata 84,64 dan model pembelajaran langsung pada kelas control memiliki nilai pretest rata-rata 56,96 dan nilai posttest memiliki rata-rata 78,39.

Peningkatan hasil belajar siswa dengan menggunakan model pembelajaran menggunakan modul dengan pembelajaran metode langsung pada mata pelajaran dasar perancangan teknik mesin kelas X SMK Semen Padang terdapat perbedaan antara hasil kelas eksperimen dan kelas control dimana pretest $\mathrm{t}$ hitung adalah 1,39 dan meningkat setelah diberikan perlakuan menjadi posttest memiliki t hitung menjadi 2,08 .

\section{Referensi}

Azhar Arsyad. Media Pembelajaran (Jakarta: PT. Grafindo Persada, 2006).

Nana Sudjana. Media Pengajaran. Bandung: Cv. Sinar Baru, 2005.

Nelvi Erizon dkk. (2019). Efektivitas Tugas Dosen Penasehat Akdemik dengan Diberlakukanya Sistem KRS Online pada Mahasiswa Jurusan Teknik Mesin FT UNP Vol 1, No. 1.

Rodhatul Jenah. Media Pembelajaran. Banjarmasin: Antasari Pers, 2009.

Asnawir dan M. Basyaruddin Usma. 2002. Media Pembelajaran. Jakarta: Ciputat Ekspress.

Departemen Pendidikan Nasional. Kamus Besar Bahasa Indonesia. Jakarta: Balai Pustaka. 2007.

Suparno dan Bulkia Rahim. Modul Pembelajaran Media Pendidikan. Padang. 2017.

Arif. S. Sadiman, dkk. 2003. Media Pendidikan: Pengertian, Pengembangan dan Pemanfaatannya. Jakarta: PT. Raja Grafindo Persada. 
Bulkia Rahim dkk. (2018). Validitas Modul Pembelajaran Model Kooperatif Tipe Jigsaw Pada Mata Pelajaran Teknik Fabrikasi Vol 1, No. 2.

Kardi, Soeparman dan Mohamad Nur. 2000. Pengajaran Langsung. Surabaya : Universitas Negeri Surabaya Universiti Press.

Mohamad Nazir. (2005). Metode Penelitian. Jakarta: Ghalia Indonesia.

NanaaSudjana, (2010). Penilaian Hasil Proses Belajar Mengajar. Bandung: Ramaja Rosdakarya.

Pusat Bahasa Departemen Pendidikan. (2002). Kamus Besar Bahasa Indonesia. Jakarta: Balai Bahasa.

Ambiyar dkk. (2019). Penerapan Model Pembelajaran Project Based Learning Untuk Meningkatkan Aktifitas dan Hasil Belajar Gambar Teknik Siswa SMK Negeri 1 Pariaman Vol 1, No. 1.

Riduwan. (2010). Belajar Mudah Penelitian. Jakarta: Alfabeta.

Sanjaya. (2006). Strategi Pembelajaran. Jakarta: Kencana Prenada Media Group.

Arwizet. (2017). Improve Learning Outcomes of Students Through Implementation of The Collaborative Project-Based Learning Model in Thermodynamics. Surabaya: Universitas Negeri Surabaya.
Sugiyono. (2006). Metode Penelitian Administrasi . Bandung: Alfabeta.

Suharsimi Arikunto. (2002). Metodologi Penelitian. Jakarta: PT. Rineka Cipta.

Jasman dkk. (2018). Persepsi Siswa Terhadap Keterampilan Dasar Mengajar Mahasiswa Program Lapangan Kependidikan (PPLK) pada Mata Diklat Gambar Teknik di SMK Negeri 5 Padang. 